\title{
Issues related to financial education of youth in a developing country (The case of Albanian Youth)
}

\author{
ARTUR RIBAJ $^{1}$, MANUELA MECE $^{2}$, VALBONA CINAJ $^{3}$, ILDA KADRIMI ${ }^{4}$ \\ ${ }^{1}$ Faculty of Economics, University of Tirana, ALBANIA \\ ${ }^{2}$ Faculty of Applied and Economic Sciences, Albanian University, ALBANIA \\ ${ }^{3}$ Faculty of Economics, Tirana University, ALBANIA \\ ${ }^{4}$ Faculty of Applied and Economic Sciences, Albanian University, ALBANIA
}

\begin{abstract}
Nowadays, financial education in a developing country believed to be important as it affects the individual well-being, the national economic growth and the stability of financial markets. Supporting financial education conveys youth empowerment through increasing their income as entrepreneurs, managing their money (incomes, salaries or other benefits) through planning spending and savings, fostering financial inclusion through recognition of financial products, risk management and protection from asymmetric information. Albanians continue to be among people who love education and invest in professions that might enable them to make more money, but they have little or no opportunities to learn about managing their money. Today, almost 4 years after the approval of the National Strategy for Development and Integration (NSDI), this paper based on data analysis of young Albanians perceptions conclude that the national objective of "empowering youth" is considered over $60 \%$ unattained, affected also by an outdated strategy on education and on development of a supporting financial education for Albanian youngsters in particular. Government, regulators and private organizations must collaborate and invest in the financial education of youth, for the future will be the product of such efforts that are made today.
\end{abstract}

Key-Words: - Financial education, money management, financial inclusion, national strategy

Received: October 18, 2019. Revised: March 2, 2020. Accepted: April 1, 2020. Published: April 13, 2020.

\section{Introduction}

Financial education is acknowledged important internationally as it affects the economic growth, the stability of financial markets and the growth of individual well-being.

The main objective of financial education is to support citizens in planning economic activity by being an active protagonist of the future, aware of managing their financial resources while being protected from speculation. Financial education is an essential tool in combating forms of economic and social exclusion, as a financial culture accessible to all categories is a benefit to society, as it reduces the risks of exclusion and encourages consumers to plan and well use their financial resources. It also helps to avoid excessive debt, as an educated society makes better decisions in choosing the right and mindful investments, minimizing risk and optimizing time for services.

Financial education is not only useful for those who have the liquidity to invest but it's an important tool especially for the disadvantaged and often incapable of any form of financial planning.

A financially educated society makes it easier to understand and better understand the policies and decision-making of public and financial institutions while increasing their faith towards them. According to Ribaj, Ilollari, Scalera, (2019) even after 10 years from the last financial crisis, people are still hesitant to deposit all their savings in banks and deposit withdrawals are considered to be the most "commonplace" activity. After the '90s, Albanians as citizens of the ex-communist countries in Balkan began to undergo major changes. The economy changed from a centralized, planned economy to a free market economy. In terms of income per capita Albanians of Balkan countries in 2018 has reached an impressive level compared to 1991, but still after almost 30 years the Albanians income are far away of the per capita income European citizens claim.

During this long transition, the ambition of becoming wealthy overnight has been a dream of 
many young people with low education pushing them into illegal activities like stealing, trading narcotics, smuggling, prostitution, and even murdering. Anecdotal evidence shows that these people hardly managed to create wealth, because wealth is a journey, not a destination. The wealth created in time is valued more than the immediate wealth, which one can lose as quickly as she earned it. Young people need to know how to build wealth by starting with saving and then investing the savings.

In transition economies like in Balkan countries (except Greece and Croatia), increasing urbanization has led to the weakening of the family networking and support, making the individual directly depending on one's savings and debt in the financial sector. On the other hand, the expansion and development of financial markets amplified the options for individuals, therefore making the financial decision more difficult for youngsters as individuals or couples today. This complication may have risen because of the pace these societies, economies and new financial instruments are developing and sophisticating, while the financial education (of Albanian population in our case) is not keeping to this pace.

\section{Methodology}

Our analysis is based on surveying 300 Albanian students, out of which 283 completed the surveys. The data were collected and analyzed by the authors of this paper in October 2019. The survey was done by telephone interviews that lasted 20 minutes on average. Respondents were not paid for their participation in the survey but were told that their responses would only be used for academic research purposes. The survey is representative of the Albanian youth population in terms of age, gender, and geographic location.

The questionnaire was designed to examine youth perception on financial education and the empowering role this education can play. The questionnaire included: introduction, qualitative (open question) and purpose-specific questions, (closed questions and single-choice questions).

For the purpose of the study and ensuring scientific representation a series of questions were used to collect demographic information (age, gender, status, employment, education, occupation, monthly income, and resources). It is worth noting that demographic data of young people of different age groups (up to 19 years of age; 20- 23; 24-27; over 28 ) shows a normal distribution; moreover, refer to the annex of this paper.

\section{Theoretical approach}

\subsection{Standard and financial education of young Albanians}

Education in the Balkan countries is one of the main areas of intervention by international actors, such as EU, WB, UNDP, etc., (Home, 2020). At regional or international meetings, experts are highlighting the development of cross-border education co-operation, skipping these countries' conflicts. However, the main response, for all countries in this study, is "Education remains a high-risk sector for corruption and political influence, especially in higher education." Education centralization is a policy found in all eight countries. The Balkans listed in this analysis and reflects the uncertain atmosphere perceived by the Balkan population (for more, see Balkan Barometer 2017) (Home, 2020).

Several scientific studies by important authors highlight the existence of a close relationship between education and income. Increasing the level of education brings additional skills to the individual, typically increasing his productivity (Mincer, 1981). The return on investment in primary, secondary and tertiary education investment for the OECD countries were 13.4, 11.3 and 11.6 percent, respectively (Psacharopoulos, 2004), (CU Scholar, 2020). From these indicators, regardless of whether they belong to OECD countries or countries similar to Albania, we find for each extra year of study they pursue in (bachelor or master) their education, their income level is increased by 11.6 percent.

But the IMF report (2017) highlighted the negative impact of brain drain and the poor standard of youth education onto Albanian economy.

The lack of educated (skilled) workers has been exacerbated by the emigration of young and relatively more educated" (IMF, 2017). While the OECD PISA report, regardless of Albanian emigration and brain drain, tests that Albania's education system is making slow progress towards achieving EU 2020 education objectives. Further, the Investment Climate Survey (ICS) concluded that $51 \%$ of large companies, $41 \%$ of exporters, and $48 \%$ of foreign companies consider skills shortages as a major obstacle in their operations, while over 35\% of companies that have adopted technology newcomers mention that manpower training is a serious limitation on their use." (ILO, 2014). 
The most important findings related to our study in the OECD report on Albania is the conclusion that: "there is still no broad approach to education about entrepreneurship and financial education as an integral part of learning in the national curriculum". Initiatives between universities, mostly private, and businesses have made little progress. According to the 2016 OECD report, "There are examples of collaboration between universities and business, considering here student work practices that can be organized during or after studies. However, recently revised policies and legal framework for higher education provide little evidence that emphasis has been placed on structured entrepreneurship learning and partnerships between business and universities, internships and work placements during undergraduate studies as well as research should be further improved, and cooperation with SMEs should be strengthened and developed further"(OECD, 2016).

Financial education to manage money wisely is a difficult task for many people, especially for individuals who lack key financial skills and who have little or no experience with financial management (Herman and Maniam, 2011). Financial education aims to make people capable of managing their cash inflows and outflows in order to manage the risks that leads to good management of their individual or family assets. To date, much of what individuals learn about personal finance comes from their families. Many individuals in life have poor financial management skills due to lack of financial education. Given that many of the financial decisions we make in life affect our well-being and that of society, the low level of financial management can be understood as a major concern directly related to financial education. We find it appropriate to note Benjamin Franklin's expression: "Beware of small expenses. A slight stream of water drowns a large ship. "The rising cost of living has made it imperative for young people to plan and utilize their financial resources efficiently, as well as not have to choose a lifestyle that they cannot afford.

Financial education is increasingly important for any individual trying to figure out how to balance his / her budget, purchase immovables like a car, a home, and pay children's education as well as keep some savings for retirement. Every person life quality is closely linked to his/her income and saving, while it is precisely the level of financial literacy that directly impacts the management of this balance.

Certain issues are highlighted in some studies related to behavioral patterns that such education can trigger. It can influence young people by making them more cynical and emotionally driven by the price and value of each product/service or activity in their lives. While the tendency for selfishness in financially educated people may increase as they measure everything from a profitable perspective, the quality of their lives is inextricably linked to the level of financial literacy that directly affects the management of future earnings. The issue we want to raise focus on the amount of information to start with. Our suggestion goes toward financial education as part of the school curriculum so that basic education is not delayed to a later stage in life or worse left to the free will of every person in Albania. At the national level, this implies greater government accountability, economic growth through investment and lower pressure on national budgets for social security networks. Expanding financial education requires a synchronized effort in keeping with the needs and cultural context of our country.

\subsection{The link between knowledge and financial behavior}

Referring to several empirical studies, we find figures showing the correlation of education level with savings and people's saving/spending patterns. According to Bennett, Porter, "Examining the Effects of Education on Financial Savings Behavior" (2018), cites: "Results show that individuals with a higher educational level are more likely to have a diversified portfolio and invest in various asset classes such as stocks, mutual funds and retirement accounts. The results also suggest that success in education has a greater positive effect on saving behavior"(CU Scholar, 2020).

Again, according to field studies, we may think that individuals' saving tendencies are driven by two predispositions, genetic-social transmission from parents to their children through lifestyle and relationships with money, and interaction with their living environment, culture and financial education which influences the improvement of individual money management.

As Henrik Cronqvist and Stephan Siegel cite in "The Origin of Savings Behavior" the genetic variant accounts for about $35 \%$ of savings behavior across individuals, and this genetic effect is stronger in countries with stronger family relationships, as well as in environments above the national average. Individuals with above-average incomes have a higher propensity to save (Dynan, et al., 2004). Also, according to Rogers (1994), Robson (2001), Netzer (2009), Brennan and Lo (2009), it is estimated that the existence and general form of 
money management behaviors are the result of natural selection, implying that preferences, consequently the savings behaviors are also genetically determined by the lifestyle parents give their children. We think that today's financial literacy of young Albanians who will be the tomorrow parents will develop this behavior as above cited authors explain. In a standard economic model, differences in savings behavior among individuals are related to differences in preferences built at school, family, and society.

The clear link between the increase of the level of education and the increase of income is also evidenced in the paper (Boshara, et al., 2015), where it is highlighted that individuals with higher education (bachelor and master) tend to generate more income than others by creating individual's premises to save. Other scientific work has shown that those individuals who have received more financial education demonstrate a greater tendency to increase their wealth by following a sound financial sustainability and behavior through the construction of long-term wealth based on an investment portfolio and therefore resulting in a lessen debt.

Although public policies implemented by governments around the globe as well as global objectives imposed from international organizations for widening the access to education, without mentioning the open platforms for education offered by worldly elite Universities are aiming to extend the accessibility of youngsters worldwide onto education as well as improve the quality of it (quite contradicting as objective) we still experience stories of students failing usual tests (PISA is a good example) or labor markets identifying real gaps in skills.

Lack of access to quality educational resources creates significant educational inequality, which later leads to income inequality (Darling-Hammond, 2001) (CU Scholar, 2020). The same principle holds for the lack of access to financial education by individuals of different social strata considering it as a factor that can bring about a significant share of wealth inequality. The study of the effect of education on financial literacy revealed that, lack of income is an important determinant of opportunities for financial literacy, but education has a significant effect (Rob \& Woodyard, 2011). According to the work of (Alessi, et al., 2011), we understand that the lack of financial literacy is attributed to low levels of savings (of parents or individuals themselves) and of not investing in financial education (in children or themselves). In the case of developing countries like Albania where parental income is very limited, it is the duty of the state to invest in mass financial education for children and young people. According to Ribaj, A. (2017) "Urgent Measures to Promote Financial Inclusion", financial education is essential for Albanians to understand what they are signing when investing. As well, implementing mandatory financial education programs for each target group reduces the social effects and financial risks of intermediaries, enhances healthy consumption, and develops sustainable financial markets (Mexhuani and Ribaj, 2018).

\subsection{Lack of financial education is reflected in low financial inclusion}

Financial education increases the ability, freedom and confidence of families and companies to better manage their finances, considering the economic and social side. Regarding the relationship between financial inclusion and demographic features of a poll in 2011 organized by BoA for financial education of Albanians, noted that the more educated (moreover, recognition of basic financial concepts) people recognize and use financial products. The same trend is observed by level of monthly household income. Also, the products are known and used more by the age group $30-59$, and $50 \%$ of interviewees admitted that when they are caught in a situation of insufficient income have chosen to borrow from friends or relatives.

According to the World Bank's Global Findex 2017, Albania marks the lowest level of access to financial services in Southeast Europe and the highest level of social inequalities between different categories in the region. Overall, $40 \%$ of Albania's adult population has a bank account, compared to $65 \%$ in Europe and Central Asia (except for highincome economies). Individuals in urban, educated, and higher welfare areas are more likely to be financially involved. Only $31 \%$ of those living in rural areas have a bank account, compared to $52 \%$ of the urban population. Similarly, account ownership is significantly lower among the adult population with primary education or less $(27 \%)$, compared to those with secondary or higher education $(56 \%)$. In addition, $23 \%$ of the poorest $40 \%$ of the population have bank accounts, compared to $52 \%$ of the richest $60 \%$. There is a $4 \%$ gender gap in bank account ownership in Albania, one of the lowest in the region.

The general population without access to banks in Albania report that they do not have an account due to insufficient funds ( $77 \%$ of those who do not have an account) and due to the high costs associated with an account (40\%). The low financial 
access in Albania is also associated with low levels of use of regulated financial services. To this end, Albania has the highest account inactivity rate, with $18 \%$ of account owners not using their accounts at all in the past year. On the other hand, the typical Albanian carries out financial activities (receives, gives or holds money) outside the regulated financial sector. It comes with such figures because in Albania also, financial inclusion is further exacerbated by the lack of symmetrical information from financial institutions (Ribaj \& Ilollari 2019). Twenty-six percent of Albanians received domestic remittances last year, but only $4 \%$ did so using an account and $24 \%$ borrowed from friends or relatives.

According to Diniz, Birochi, and Pozzebon (2011) "To overcome the tensions and restrictions related to people's high indebtedness and the lack of information, we think that some sort of educational action will be needed, encompassing necessities of the local actors and characteristics of financial services". While, the complexity of financial operations and the use of money for centuries have been and are subject to much interest by consumers, scholars, theologians, lenders, etc. The German sociologist Georg Simmel, who is still researched in modern times, wrote two books: The Philosophy of Money (1907) and Sociology (Wolff, 1950). He wrote about the challenges that a money economy brings to the way people interact with one another.

On the one hand, money rationalizes society, mathematizes it, or, in its words, aims to "turn it into an arithmetic problem" (Wolff, 1950). Money, according to Simmel, (1978) depersonalizes social interaction by introducing abstraction and anonymity. On the other hand, he points out that a money economy requires a great deal of confidence, to a much greater degree than what was required when we say bartering was the means of exchange. His observations are as true as they were 100 years ago (Home, 2020). According to Friedman (1953), in classical economics, informed consumers provide the "control and balance" that keeps unscrupulous sellers out of the market, and we can understand that money management and asset management skills cannot be explained by "chance" of events (exp., inheritance, health status, etc.).

We identify that financial education is important first for the individual himself and then for his family as well as for the whole community through the sustainable economic development of the country. Extended financial literacy best serves financial planning, smart family budgeting that, through management of expenses, savings, insurance, and investments, help increase the quality of life of individuals in the long run.

We analyze that every well-educated individual is less exposed to financial risks. While young people with no financial literacy have a harder financial life, they fail to save and often get into unhealthy debt. In many cases, they owe debt to relatives (family and social circle), based on trust, which has often become a source of conflict, bringing high social costs for them. For young Albanians, financial education plays a key role in overcoming the challenge of being financially excluded from regulated financial markets. Also, Albania does not have an official assessment for the level of financial education neither for its citizens nor for its youth. To establish a real understanding to what extent is the financial education involved in the country and where obstacles stand, Albania need a national project for assessment and then drafting the strategy for supporting a national financial education.

Through financial education the Albanian youth will boost their financial inclusion supported by digital financial services, financing of small and medium-sized enterprises, etc. The level and quality of financial inclusion has a significant impact on opportunities for further progress that will support and facilitate greater degree of stability of the financial stability and sustainable growth of the Albanian economy.

\section{Results and discussions}

\subsection{How empowered is the Albanian youth today compared to 2014 ?}

Albanians continue to be among the most educated and affluent peoples with positive human development indicators (HDS). In 2019, HDI for Albania was 0.791 with an average of 10.1 years of schooling ranked at $69^{\text {th }}$ world list by UNDP, while in 2013, HDI was 0.716. According to 2013 statistical data of INSTAT, Albania still has a young middle age compared to other European countries, where about $30 \%$ of the population belongs to the age group of 15-29. This age group constitutes the largest grouping of active force in society and the capable labor force and the future of Albania for generations to come.

Political parties in the election campaign have repeatedly stated that youth prosperity is in the spotlight. Governments develop unproven strategies, unenforceable and ultimately unproductive. The result is that young Albanians continue to feel insecure and powerless in this country. Indicative is the continued migration of young people for many 
years. For Albania, human resources, like any other country, are the most important. Albanians along with good governance systems underpin the country's healthy economic growth. NSDI-II quotes: "To maintain a sustainable growth of human development, welfare and social cohesion, NSDI-II for the period 2015-2020 will focus on nine key sectors...". The education sector accounts for the largest share of national budget resources, and the 'Youth Empowerment' sector is part of the NSDI. Notwithstanding these two sectors, after almost 4 years of this strategy, they continue to face the same problems as the perception of Albanian youth in graphic 1, which reflects the distribution (from 1-5) according to the rating given by young people interviewed about the question how empowered you feel today compared to 4 years ago. Their responses were in $64 \%$ of the cases the rating is not at all low, while $20 \%$ on average and $16 \%$ on good and very good. As has generally been the case in Albania, strategy development has been a formality for having a document to present as part of international projects and to remain in the shelves of state institutions. Despite the need to survive, according to some studies, the lack of financial literacy around the world promotes the immediate bankruptcy of individuals or families in the event of economic crises (figure 1). The deterioration of macroeconomic indicators and, moreover, for developing countries of Balkan, make Albanian young people lose hope for employment and the creation of their families. Even those who are employed are affected by negative behaviors and expectations about decisions about their future by not taking responsibility because of ignorance that promotes insecurity. The task should be for the respective institutions to support young people for a better future for themselves and the country.

Financial education is a potential variable that has an impact on individual financial decisionmaking and money management skills. The more educated individuals are, the more risk averse they are and the higher their ability to make the financial decisions they make. Also, promoting financial education plays a positive role in money management skills and in encouraging saving behavior. The research data provide a causal explanation for the stress phenomena by highlighting that financial management can affect an individual's mental and physical health. So low income and poor financial management can lead to anxiety and stress in the lives of young Albanians. All this often causes young Albanians to seek a solution through emigration to other EU countries or North America.

\subsection{What is the level and need of financial education and financial inclusion of young Albanians?}

Young people surveyed through the question "How financially educated do you feel today?" with distribution (1-5) responded that in 58\% of cases the rating is for the indicator not at all and poorly educated, and $32 \%$ belong to the indicator that they consider having financial literacy on average. Despite the tendency to appear better than other Balkans people, the responses of Albanian youth when asked about the reasons for their low level of financial education, they argue that they have had no tradition of learning about management of money in school, family or society, as well as the amount of money they have available is mostly money for their basic needs (subsistence). While $10 \%$ of them consider themselves to have good and very good financial education. Following this question, the next question posed: " How necessary is financial education for young people?" has a distribution (from 1-5) according to the rating given by the young respondents and shown in graph 2 . In $81 \%$ of cases the assessment is that financial education is necessary and very necessary for young Albanians, while $10 \%$ consider it to be moderately needed, when only $9 \%$ belong to indicators 1 and 2 which consider financial education as little or no need. The data from this question give us positive hope that young Albanians have a clear need for financial education as a support for their financial decisions that condition their quality of life (figure 2). Those young people who make up the majority qualified by this survey point out that the Albanian youth are looking for the right way to offer themselves a better quality of life. According to the comments, most respondents have come to this conclusion as they have occasionally felt the deficiencies that they have about the financial products and financial decisions that they or their relatives have to make. Respondents stated that financial intermediary employees were willing to provide some financial advice, but in the perception of most respondents they considered that financial intermediary employees attempted to simply sell you products rather than sell them. They give you financial advice to make the most profitable decision in the interest of consumers.

Whereas according to the data presented in graphic 3, the distribution of youth according to the knowledge they have about the fundamentals of Money Management is given. Education plays a 
positive role in enhancing the quality of life of young people. Moreover, when financial education is part of general education, it brings about increased money management skills among young people and encourages saving and investment behavior. In $88 \%$ of the responses, young people stated that they did not have the basic knowledge of money management during school education or seminars. While $12 \%$ of them stated that they have acquired basic knowledge about money management in school and are mainly those who have attended economics school. In their answers to the open-ended questions (figure 3) that accompany this question, young people do not identify any financial institution or association that has invited them to provide financial literacy. In some activities that they have been mainly informed by social media have identified that they were mainly promotional activities for the organizers of the activities rather than in the service of financial education. Young people have acquired knowledge about money management mainly from family and society and very little from school or other organizations (financial institutions, associations, etc.).This is also evidenced by the question where young people were asked to answer whether they were invited and involved in financial education support projects and the promotion of financial inclusion of young people from different projects or organizations with a distribution (from 1-5) as alternatives.

Response data shows that in $72 \%$ of cases the rating is for indicator 1 , in $14 \%$ of cases the rating is for indicator 2 , in $8 \%$ of the cases the rating is for indicator 3 , in $6 \%$ of the cases the rating is for indicator 4 , while $0 \%$ belongs to indicator 5 . While the minimum necessary for good personal financial management is having a bank account. To know the level of financial education and its expression through the level of financial inclusion, the young respondents were asked the simple question about the number of current accounts, savings accounts, debit cards and other financial products they own. Graphic 4 shows the distribution by number of bank accounts and financial products they own, with $18 \%$ having more than two products, $46 \%$ having no product, $18 \%$ having two products, and only $18 \%$ having one product.

As can be seen (figure 4) from the graph we have the expression of the lack of at least one bank account among the young respondents. This indicator is at a very high level and not at all normal from the standpoint of what some NGOs or entities advertise for their hard work on financial education or inclusion and empowerment strategies for the
Albanian youth. Also, this indicator is very high when the answers belong to the youth of a country geographically located in the middle of Europe and with aspirations to become a member of the EU. Following is the identification of young people's knowledge and involvement in graphic 5. The distribution of youth responses on what they use their money for in categories 1 through 7 is presented. The indicators are as follows: $2 \%$ are for category 1 that will lend to relatives or friends; $10 \%$ are for Category 2 that they will leave in their savings account in the bank; $24 \%$ are for category 3 to buy clothing, accessories and entertainment; $6 \%$ are for category 4 that will invest in business; $34 \%$ are for category 5 to buy food ; $6 \%$ are for category 7 that they will spend on other requirements; and $18 \%$ are for category 6 that will pay rent and tuition. For Albanians this indicator is somewhat lower also because young people continue to have a tradition of living with their parents, who inherited their apartments for free by state properties (in the former centralized economic system).

All data obtained from the survey (figure 5) and analysis highlight the lack of role that pre-university education and financial institutions should play, which should be more involved in enhancing financial literacy of young Albanians, to ensure that all individuals involved in the educational process to obtain the necessary tools for managing personal finances. Thus, they can become productive members of societies, contributing in prospering and sustainable economic growth of their country, starting first with their financial and social health and then for the societies. Following the shortcomings and the need for financial education, the young Albanians were asked the question " Should financial literacy for students in preuniversity education be significantly increased?" According to the presentation in graphic 6, following, in $89 \%$ of youth responses, they were very enthusiastic about adding such a subject.

Whereas $11 \%$ were not enthusiastic (figure 6) as they stated that in high school the subject of "Applied Economics" is developed and had their reservations about the clarity and effectiveness that this subject has for young people, since almost nothing has served you in life their daily. Adding here their opinions on the qualification of teachers who are mostly not graduates of economics or do not even know financial products themselves.

The good financial education received at school will help young people, their parents, as well as themselves tomorrow when they will be parents. Also, having a family financial culture for managing cash and personal finances is very important and 
supports a healthy financial and social life. Finally, financial literacy has a significant impact on financial decision making and risk management skills of young people.

\section{Conclusion}

- Youngsters in Albania are interested for a good education that provides them decent employment in terms of incomes. They expect to improve their ability to manage such income and ensure appropriate financial inclusion. This study identifies some other issues, such as: early and continuing financial education, family and social /cultural context, poor access to symmetrical financial information, trust-conscious choice to avoid having a formal banking relationship, etc.

- Financial education should be considered an imperative need for every Albanian, as they must make financial decisions and some of them have long lasting effects. Decision-making under financial ignorance causes individual and family financial crises. They are accompanied by irreversible psychological and social consequences that negatively contribute to the performance of the economy of the country and the whole society.

- To date sporadic results can be counted on the actions undertaken by schools, nonprofits or other institutions, different than what they advertise. The governments are required to develop appropriate strategies and structures for the implementation of effective dedicated financial education programs that truly target the needs of low- and middleincome individuals. While organizations (as NGOs, etc.) that claim to support the vulnerable categories of our society with financial education, is better either to change approach or stop spending funds that contribute only to the falsehood of their corporate social responsibility.

- The future of the financial system will depend on consumer preferences. Consumer preferences are influenced by financial culture and education which for Albanians in the past proved that a poor financial culture led to bad outcomes for consumers and markets, and after that leading to the country's economic and political instability. Public, private institutions and regulators must collaborate and invest in the financial education of society, because the future will be the product of the investments that are made today.

- "Education development strategy for the period 2014-2020" adopted by DCM No. 11, dated 11.1.2016 is nearing end, work on drafting a new education development strategy for the period 20202026 should consider setting measurable objectives and structures responsible for boosting financial education for Albanian youth.

\section{References:}

[1] Adult Learning Australia. 2020. Home. [online] Available at: www.ala.asn.au

[2] Bennett, Porter, "Examining the Effects of Education on Financial Savings Behavior" (2018). Undergraduate Honors Theses. 1620

[3] Card, D. The casual effect of education on earnings. Department of Economics, University of California at Berkeley. 1999

[4] Darling-Hammond, L. Unequal opportunity: Race and Education. The Brookings Institute. 1998

[5] Diniz, E., R. Birochi, and M. Pozzebon, Triggers and a barriers to financial inclusion: The use of ICT based branchless banking in an Amazon County Electron Comm. Res. Appl. 2011 Doi:10.1016/j.elerap.2011.07.006

[6] Dynan, K., Sinner, J., \&Zeldes, S. Do the rich save more? Journal of Political Economy, 112(2), 2004

[7] Friedman, Michael. Explanation and scientific understanding, Journal of Philosophy. 1974

[8] Friedman, Milton. The methodology of positive economics, pp. 290 of his Essays in Positive Economics. Chicago: Chicago University Press. 1953

[9] Henrik Cronqvist and Stephan Siegel. Journal of Political Economy. Vol. 123, No. 1 February 2015, pp. 123-169.

[10] Hout, M. . Social and economic returns to college education in the united states. Annual Review of Sociology 38(379-400), 2012

[11] Herman, M. and Maniam, B.,. Personal Finance Education: An Early Start to A Secure Future. College Teaching Methods \& Styles Journal (CTMS), 3(1), p.39, 2011

[12] Mincer, J., Human capital and economic growth. National Bureau of Economic Research. 1981

[13] Mexhuani, F. and Ribaj, A., National Financial Inclusion Strategy for Fighting Against Poverty and Enhancing Sustainable Economic Development in Albania. European Journal of Marketing and Economics, 1(2), p.57, 2018

[14] Psacharopoulos, G., Patrinos, H.. Returns to investments in education: A further update. Education Economics, 12 (2), 2004

[15] Personal Finance Fourth Edition, KapoorDlabay-Ahmad-Hughes, 2009

[16] Ribaj A, Ilollari O., Asymmetric Information versus Banks' Costumer Trust, Albania case 
linked with SEE countries, WSEAS Transactions on Business and Economics, pp. 288-297, Volume 16, 2019 http://www.wseas.org/multimedia/journals/eco nomics/2019/a585107-694.pdf.

[17] Ribaj Artur, Ilollari Orkida, Scalera Francesco, The unethical banking costs distrust of bank customers (Albania case as a model for SEE countries)", WSEAS Transactions on Business and Economics, Volume 16, 2019, pp. 582-592

[18] Sullivan, J., Wolla, S.. Education, income, and wealth. Federal Reserve Board of St. Louis, 2017

[19] The Balkan Forum. 2020. HOME. [online] Available at: <https://thebalkanforum.org/.

[20] The philosophy of money Third Enlarged Edition, Georg Simmel

[21] The complete idiot's guide to getting rich second edition, Larry Waschka

[22] The Sociology of Georg Simmel, Kurt H.Wolff.

[23] Tilak, J. B. G., Rates of return to education and income distribution. De Economist, 137(4), 454-465, 1989 


\section{Annex}

\subsection{Figures}

\section{How empowered is the Albanian youth in 2019 compared to 2015 ?}

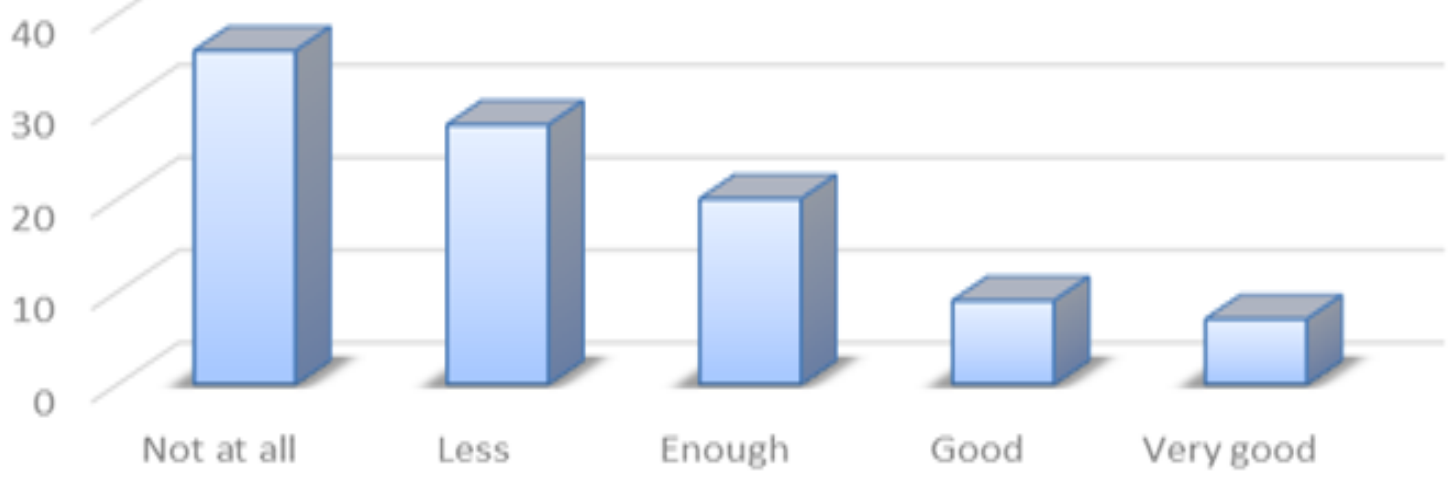

Fig 1. How empowered is the Albanian youth in 2019 compared to 2015?

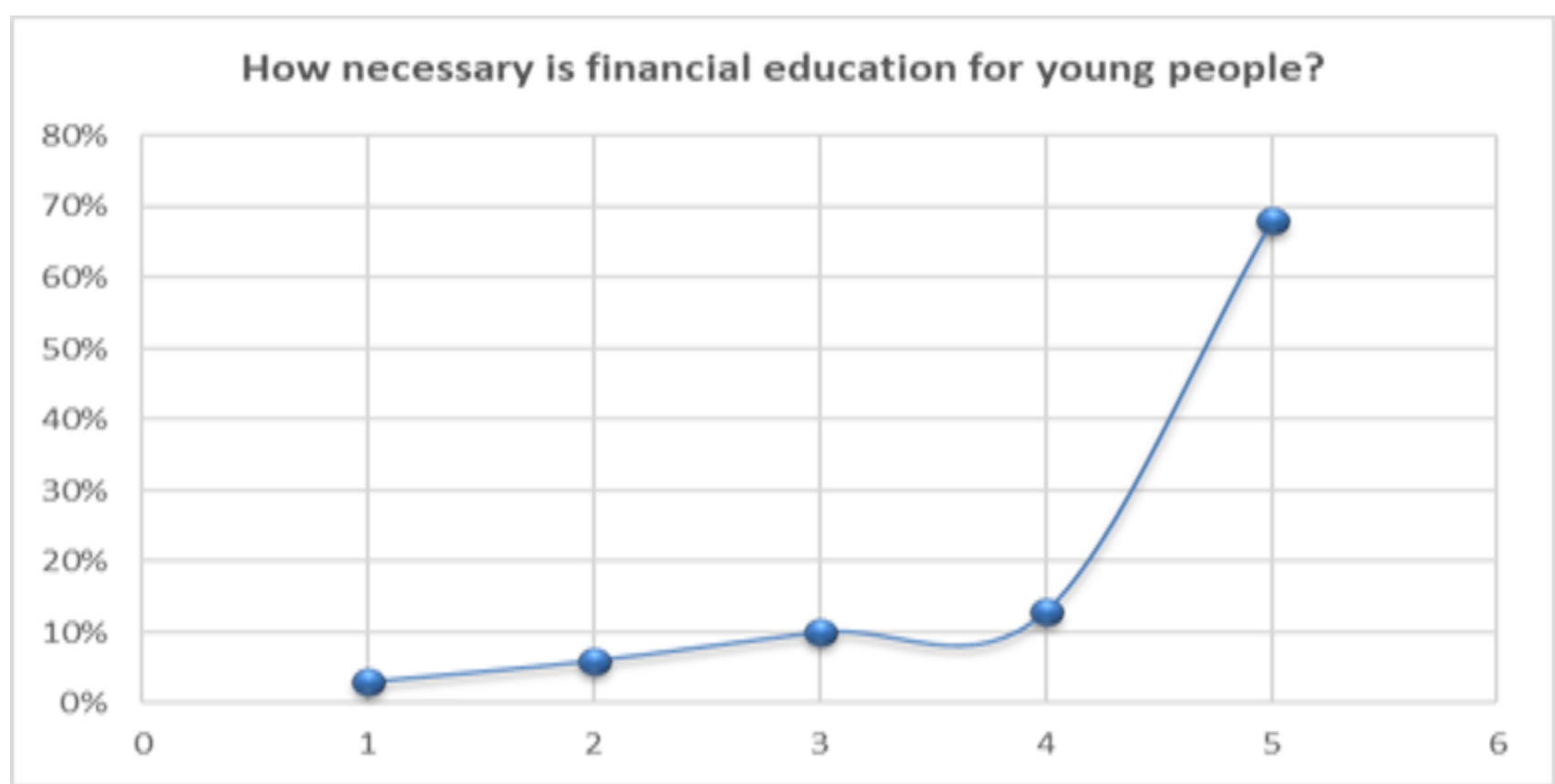

Fig 2. How necessary is financial education for young people? 


\section{Have you received the necessary basic knowledge of financial education at school?}

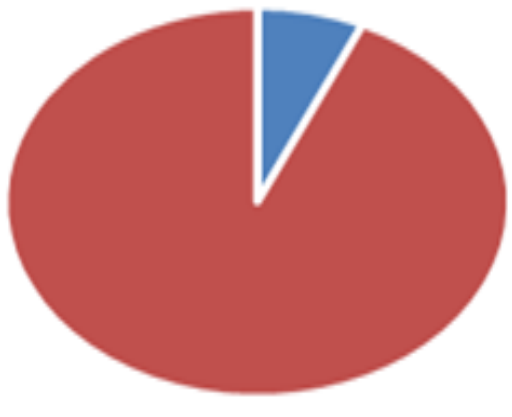

- YES $=\mathrm{NO}$

Fig 3. Have you received the necessary basic knowledge of financial education at primary and secondary school?

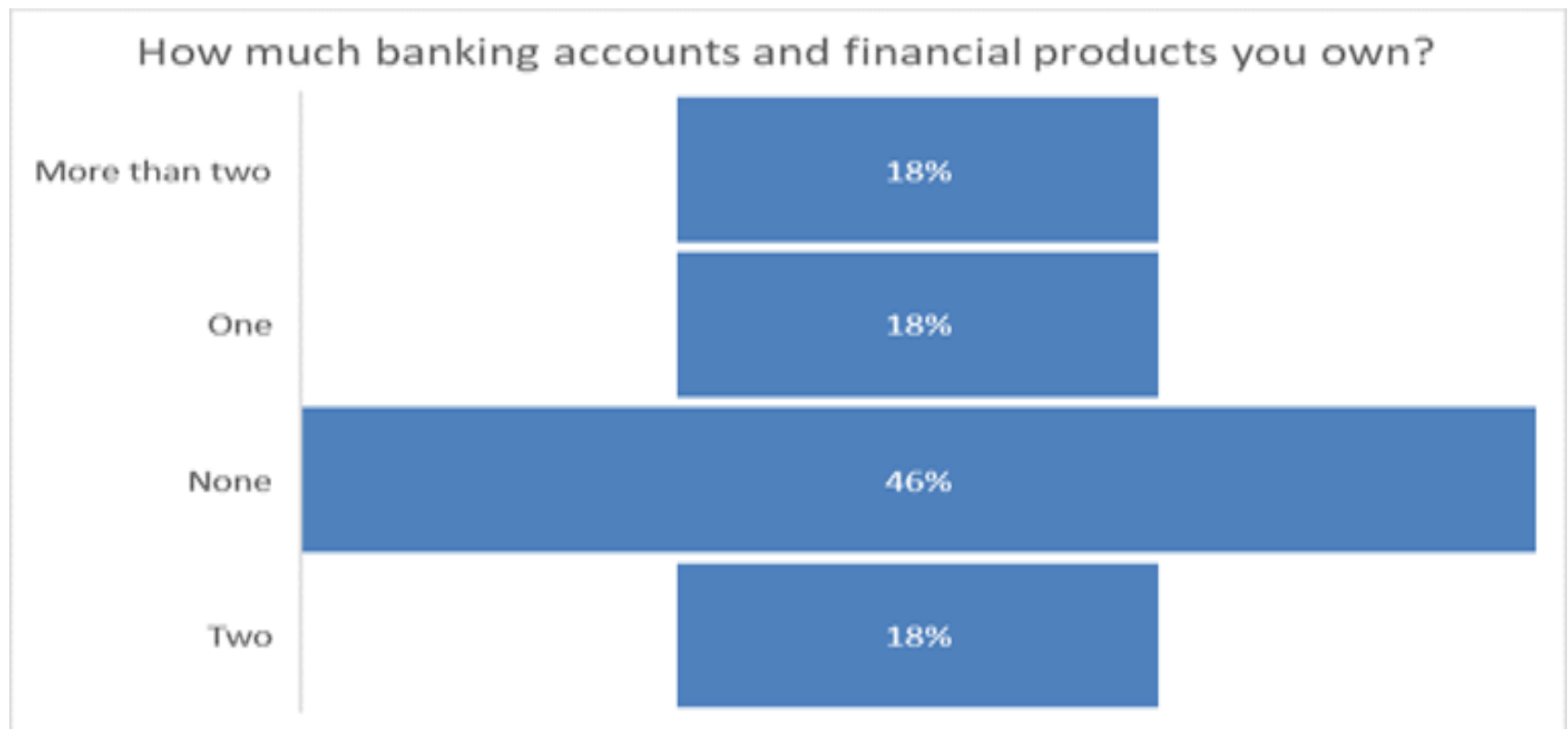

Fig 4. How much banking accounts and financial products you own? 


\section{Where do you spend or invest your monthly income?}

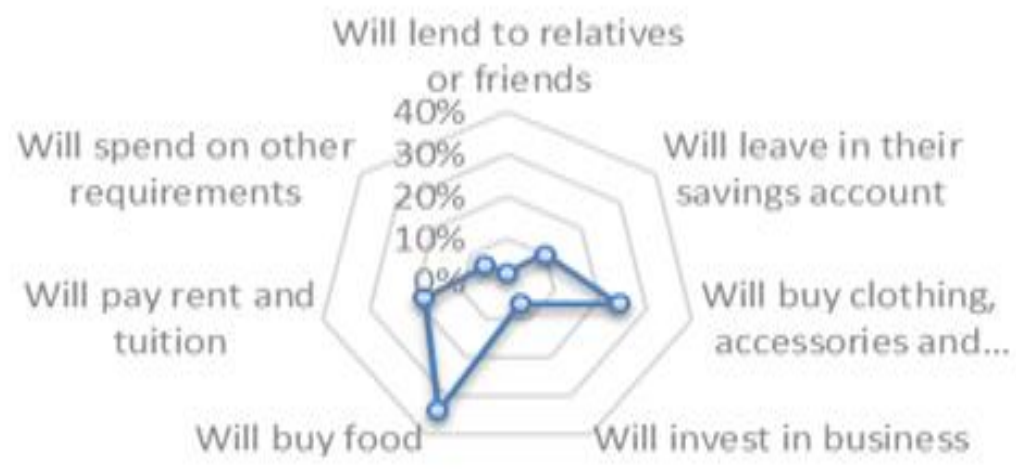

Fig 5. Where do you spend or invest your monthly income?

\section{Should financial literacy for students \\ in pre-university education be significantly increased?}

$100 \%$

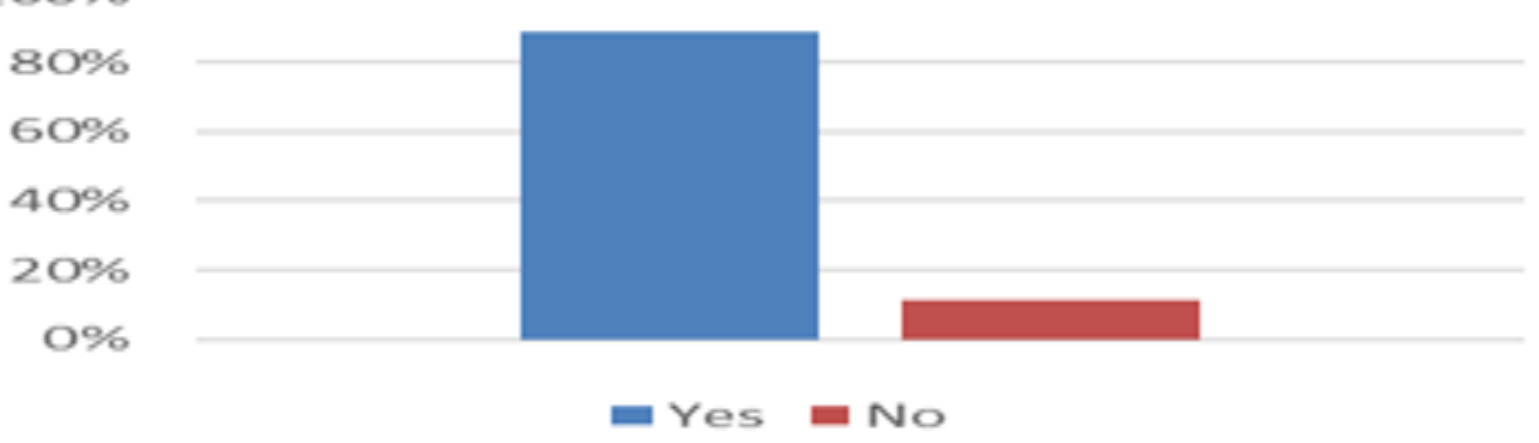

Fig 6. Should financial literacy for students in pre-university education be significantly increased?

\subsection{Data for the sample}

- Distribution by gender, with $56 \%$ of respondents being female and $44 \%$ male. There is a higher presence of female gender, which is also related to the greater emigration of Albanian male youth of this age group.

- $\quad$ Youth age distribution, where $4 \%$ are up to 19 years old, 54\% are 20-23 years old, 34\% are 24-27 years old, $8 \%$ are 28 years old and over. The age group of 20-23 years and the age group of 24-27 years are also dominant in the given responses. This is also the most active and current age for pursuing bachelor and master studies, where they receive financial education. It is mainly after this age that young people distance themselves from studies.

- Distribution by status of young people, with $50 \%$ of them single, $12 \%$ married, $22 \%$ engaged, and $16 \%$ living together. Being single makes them more independent and indifferent to long-term financial decision making.

- Distribution by level of education of young people, with $42 \%$ having a bachelor's degree, $28 \%$ with a secondary education, $20 \%$ with a master's degree, and $10 \%$ with primary education only. Most of the young people interviewed have bachelor's and master's degrees.

- Distribution according to the source of the income, where $62 \%$ are from work in private sector, 
$20 \%$ are from work in public sector, $18 \%$ are from work in immigration and other sources. According to statistics the number of employees in the private sector accounts for $83 \%$ of the total number of employees.

- Distribution by level of their personal or family income, with $60 \%$ having insufficient income, $30 \%$ with enough income, and only $10 \%$ with high income. According to the data, the insufficient level of income dominates above the average, indicating that Albanians are still far from the level of income equilibrium. 